\title{
Albumin/globulin ratio is negatively correlated with PD-I and CD25 mRNA levels in breast cancer patients
}

This article was published in the following Dove Press journal:

OncoTargets and Therapy

\author{
Chao Liul,* \\ Wei Wang ${ }^{2, *}$ \\ Xiangying Meng' \\ Bing Sun' \\ Yang Cong' \\ Jiannan Liu' \\ Qian Wang' \\ Guangxian Liu \\ Shikai Wu' \\ 'Department of Radiation Oncology, \\ Affiliated Hospital of Academy of \\ Military Medical Sciences, Beijing, \\ People's Republic of China; ${ }^{2}$ Cancer \\ Therapy Center, Affiliated Hospital of \\ Academy of Military Medical Sciences, \\ Beijing, People's Republic of China \\ *These authors contributed equally \\ to this work
}

Background: Previous studies have demonstrated the prognostic value of globulin (GLB), albumin (ALB), the ALB/GLB ratio (AGR), body mass index (BMI), hemoglobin (Hb), and prognostic nutritional index (PNI) in breast cancer. The underlying mechanism has been investigated by examining the impact of nutritional parameters on T cells, natural killer cells, and dendritic cells, but little is known about their effect on checkpoint molecules.

Methods: Here, we investigated the correlation of mRNA expression of programmed cell death protein 1 (PD-1), cluster of differentiation 28 (CD28), cytotoxic T-lymphocyte antigen-4 (CTLA-4), and cluster of differentiation 25 (CD25) with AGR, ALB, GLB, total protein, pre-ALB, Hb, BMI, and PNI in the peripheral blood of breast cancer patients. One hundred and three patients and 21 age- and sex-matched healthy controls were enrolled. Quantitative real-time PCR was used to test relative mRNA expression.

Results: The results indicated that the mRNA levels of PD-1 and CD25 were 5.2- and 3.3-fold higher in patients with low AGR than in those with high AGR $(P<0.05)$. The mRNA levels of PD-1 were 3.5-fold higher in patients with high GLB than in those with low GLB $(P<0.05)$. In addition, breast cancer patients had higher expression levels of PD-1, CD28, CTLA-4, and CD25 mRNA in their peripheral blood compared with healthy volunteers $(P<0.05)$.

Conclusion: These results suggest that AGR is negatively correlated with PD-1 and CD25 mRNA levels, while GLB is positively associated with PD-1 mRNA levels. Nutritional status in breast cancer patients may influence the PD-1 pathway and have implications for the optimization of cancer therapy.

Keywords: nutrition, AGR, globulin, immune checkpoint, PD-1, CTLA-4, breast cancer

\section{Introduction}

Breast cancer is the most commonly diagnosed malignant tumor in women worldwide. ${ }^{1}$ The nutritional status of cancer patients is an important factor influencing their prognosis. Previous studies have demonstrated that high levels of globulin (GLB), one of the major proteins in humans, were correlated with poor survival in patients with breast cancer and rectal cancer., ${ }^{2,3}$ By contrast, increased albumin (ALB) levels and ALB/GLB ratio (AGR) were independently associated with better outcomes in various cancers, including breast cancer, non-small-cell lung cancer, renal cell carcinoma, and laryngeal squamous cell carcinoma. ${ }^{4-10}$ In addition, body mass index (BMI) has been suggested as a prognostic value for breast cancer, as patients with very high or low BMI have poor survival compared with normalweight patients. ${ }^{11,12}$ Hemoglobin $(\mathrm{Hb})$ also has prognostic relevance in breast and colorectal cancers. ${ }^{4,13}$ Prognostic nutritional index (PNI), which is calculated as 
$10 \times$ serum ALB $(\mathrm{g} / \mathrm{dL})+0.005 \times$ total lymphocyte count $\left(\right.$ per $\mathrm{mm}^{3}$ ), has prognostic value in breast cancer. ${ }^{14,15}$

The underlying mechanism explaining why nutritional status influences the prognosis of cancer patients has frequently been investigated with respect to immune-related factors. A previous study revealed that ALB could promote MHC II expression and consequently activate $\mathrm{T}$ lymphocytes. ${ }^{5,16,17}$ GLB has been found to have a negative effect on immunity by inhibiting cell-mediated cytotoxicity and the function of natural killer (NK) cells. ${ }^{18}$ In lean women, leptin levels are decreased, leading to the accumulation of regulatory $\mathrm{T}$ cells and macrophages that secrete anti-inflammatory molecules, including interleukin-4 (IL-4), interleukin-10 (IL-10), and transforming growth factor- $\beta$ (TGF- $\beta$ ). ${ }^{19,20}$ By contrast, obese people have reduced number and function of NK cells, $\mathrm{CD} 8^{+}$ $\mathrm{T}$ cells, $\mathrm{CD} 4^{+} \mathrm{T}$ cells, and dendritic cells. ${ }^{21,22}$

However, the correlation between nutritional parameters and co-inhibitory and co-stimulatory molecules is unknown. Here, we investigated the association between nutritional factors and mRNA expression of programmed cell death protein 1 (PD-1), cluster of differentiation 28 (CD28), cytotoxic T-lymphocyte antigen-4 (CTLA-4), and cluster of differentiation 25 (CD25) in the peripheral blood of breast cancer patients. Nutritional parameters included GLB, ALB, AGR, total protein (TP), pre-ALB (PA), Hb, BMI, and PNI.

\section{Patients and methods Patients and blood collection}

This study was approved by the Ethics Committee of the Affiliated Hospital of Academy of Military Medical Sciences. Patients and healthy volunteers provided written informed consent. One hundred and three breast cancer patients were enrolled in this study. All were admitted to the Affiliated Hospital of Academy of Military Medical Sciences between November 20, 2015, and March 14, 2016. We enrolled patients who had pathological malignant breast tumors. Exclusion criteria were as follows: patients with inflammatory breast cancer, other tumors, hematological disease, infection, inflammatory disease, liver disease or renal disease, or metabolic disease, and patients for whom no pretreatment blood samples were available. In addition, we included 21 age- and sex-matched healthy controls. Peripheral blood was collected from treatment-naïve patients and healthy controls.

We collected clinicopathological information for the 103 breast cancer patients from medical records. This included tumor pathology, age, tumor grade, tumor node metastasis (TNM) stage (seventh edition of the World Health Organization criteria), ${ }^{23}$ tumor grade, estrogen receptor (ER) and progesterone receptor (PR) status (positive status was defined as $>10 \%$ positive invasive tumor nuclei), human epidermal growth factor receptor-2 (Her-2) status (positive when the immunohistochemistry score was $3+$ or fluorescence in situ hybridization confirmed positivity), and Ki-67.

\section{Nutritional parameters}

We chose GLB, ALB, AGR, TP, PA, Hb, BMI, and PNI as parameters to evaluate the nutritional status of breast cancer patients. These nutritional parameters were obtained from our clinical laboratory. According to the criteria of our clinical laboratory, cut-off values for GLB, ALB, AGR, TP, PA, and $\mathrm{Hb}$ levels were $30 \mathrm{~g} / \mathrm{L}, 40 \mathrm{~g} / \mathrm{L}, 1.5,65 \mathrm{~g} / \mathrm{L}, 200 \mathrm{mg} / \mathrm{L}$, and $110 \mathrm{~g} / \mathrm{L}$, respectively. BMI was calculated as weight/ height ${ }^{2}\left(\mathrm{~kg} / \mathrm{m}^{2}\right)$ and categorized as high $(\mathrm{BMI} \geq 25)$ and low $(\mathrm{BMI}<25)$. PNI was calculated as $10 \times$ serum $\mathrm{ALB}(\mathrm{g} / \mathrm{dL})+$ $0.005 \times$ total lymphocyte count $\left(\right.$ per $\left.\mathrm{mm}^{3}\right)$.

\section{Experimental procedures for quantitative real-time PCR}

Whole blood was mixed with red blood cell lysis solution and inverted. The mixture was centrifuged at 2,000 rpm for $5 \mathrm{~min}$, and the cell pellet was kept at the bottom of the tube. These steps were repeated until the red blood cells were fully lysed. Then, we mixed the cells with $1 \mathrm{~mL}$ TRIzol and stored the mixture at $-80^{\circ} \mathrm{C}$ before RNA extraction. RNA extraction and cDNA synthesis were performed as previously described. ${ }^{24}$ Quantitative real-time PCR was performed to detect PD-1, CD28, CTLA-4, and CD25 mRNA. Forward and reverse primers for PD- 1 were $5^{\prime}$-GGTGTGAGGCCATCCACAA- ${ }^{\prime}$ and 5'-CCATTCTGTCGGAGCCTCTG-3', respectively; those for CD28 were 5'-CGCAGTGGCTCATGCTTGTA-3' and 5'-TCTCATGCCTCAGCCTCTTG-3', respectively; those for CTLA-4 were 5'-GCTGACAGCCAGGTGACTGAA-3' and 5'-TGAGCTCCACCTTGCAGATG-3', respectively; and those for CD25 were $5^{\prime}$-ATGGCTGCAACCATGGAGAC-3' and 5'-TCTGTTCCCGGCTTCTTACC-3', respectively. $\beta$-Actin was used to normalize target gene expression, and forward and reverse primers for $\beta$-actin were $5^{\prime}$-ACG TTGCTATCCAGGCTGTG-3' and 5'-CGCTCGGT GAGGATCTTCAT- $3^{\prime}$, respectively. The $2^{-\Delta \Delta C t}$ method was used for the calculation of relative mRNA expression.

\section{Statistical analysis}

We used the Mann-Whitney test to compare the PD-1, CD28, CTLA-4, and CD25 mRNA levels in breast cancer patients with those in healthy controls. Student's $t$-test was used to 
evaluate the correlation between nutritional parameters and clinicopathological characteristics in breast cancer patients. The 103 breast cancer patients were divided into two groups (high and low) by the median value of each nutritional parameter. The Mann-Whitney test was then used to compare the mRNA levels of PD-1, CD28, CTLA-4, and CD25 in these two groups. Statistical Package for Social Sciences (SPSS), version 23.0 (IBM Corporation, Armonk, NY, USA), was used to analyze data. A $P$-value $<0.05$ was considered statistically significant.

\section{Results}

\section{Patient characteristics}

We enrolled 103 breast cancer patients with a median age of $51(22-75)$ years. There were 73 invasive ductal carcinomas, eight invasive lobular carcinomas, 17 invasive carcinomas, and five malignant tumors with other pathological types. The numbers of patients with TNM stage I-IV were 11, 42, 11, and 39 , respectively. There were 58 patients with tumor grades I and II and 18 with tumor grade III. Among the patients, 75 were $\mathrm{ER}+, 25$ were ER-, 66 were $\mathrm{PR}+, 37$ were PR-, 28 were Her-2+, and 75 were Her-2-.

\section{Levels of nutritional parameters and mRNA expression of immune parameters}

Figure 1 shows the numbers and proportions of patients whose nutritional parameters were less than the cut-off value. There were $58(56 \%)$ patients with abnormal GLB, 57 (55\%)

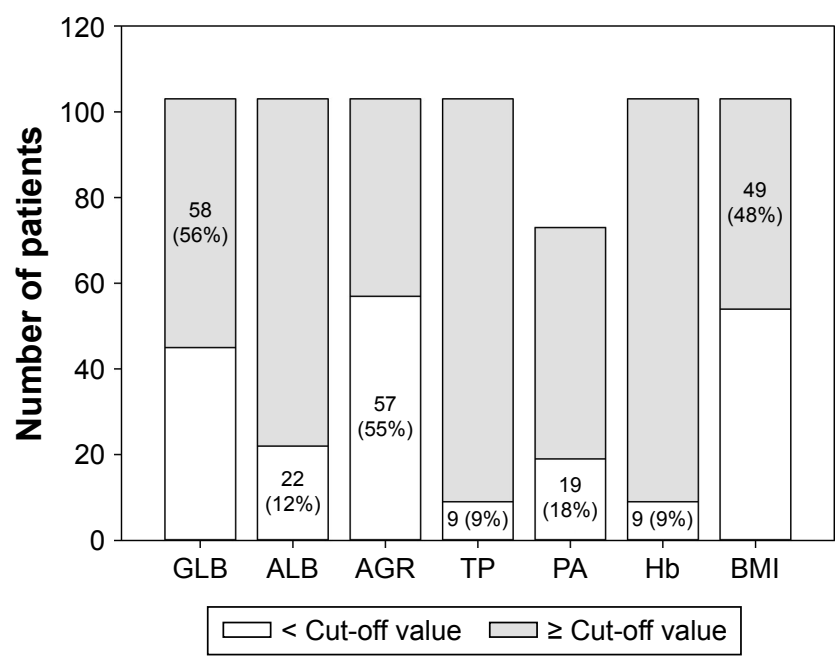

Figure I Number and proportion of patients with abnormal nutritional status according to cut-off values of nutritional parameters.

Notes: Abnormal states of nutritional parameters: GLB $\geq 30 \mathrm{~g} / \mathrm{L} ; A L B<30 \mathrm{~g} / \mathrm{L}$; AGR $<1.5 ;$ TP $<65 \mathrm{~g} / \mathrm{L} ; \mathrm{PA}<200 \mathrm{mg} / \mathrm{L} ; \mathrm{Hb}<110 \mathrm{~g} / \mathrm{L} ; \mathrm{BMI} \geq 25 \mathrm{~kg} / \mathrm{m}^{2}$.

Abbreviations: GLB, globulin; ALB, albumin; AGR, albumin/globulin ratio; TP, total protein; PA, pre-albumin; $\mathrm{Hb}$, hemoglobin; BMI, body mass index. patients with unusual AGR, and $22(12 \%)$ patients with low ALB. Forty-nine (48\%) patients had high BMI ( $\geq 25)$. There were only nine (9\%) patients with low $\mathrm{TP}$ and $\mathrm{Hb}$.

For PD-1 mRNA expression, healthy people showed a significant reduction compared with breast cancer patients ( $P=0.019$, Figure 2A), and the mRNA levels of CD28, CTLA-4, and CD25 were significantly elevated in patients compared with healthy volunteers $(P<0.001$, Figure $2 \mathrm{~B}-\mathrm{D})$.

\section{Association between nutritional parameters and clinicopathological characteristics}

The correlations between eight nutritional parameters and clinicopathological characteristics are shown in Table 1. In Stage IV breast cancer patients, TP was significantly decreased (72.08 \pm 5.41 vs 74.54 $\pm 5.33, P=0.024)$ compared with Stage I-III patients; ALB was reduced (41.23 \pm 3.93 vs $44.71 \pm 3.57, P=0.001)$; AGR was diminished significantly $(1.37 \pm 0.26$ vs $1.55 \pm 0.39, P=0.014)$; and $\mathrm{Hb}, \mathrm{PA}$, and PNI were all decreased $(P<0.01)$. Patients with poor tumor differentiation had lower BMIs than the opposite group $(24.14 \pm 2.09$ vs $25.66 \pm 3.41, P=0.025)$, and there were increased TP levels in PR- breast cancer patients compared with PR+ cases $(75.13 \pm 5.20$ vs $72.83 \pm 5.47, P=0.036)$. No other significant correlation was found.

\section{Correlation between nutritional parameters and expression of immune parameters}

Patients with high GLB showed increased mRNA levels of PD-1 compared with those with low GLB, with a fold increase of 3.5 ( $P<0.05$, Figure 3A), whereas GLB was not significantly correlated with CD28, CTLA-4, or CD25 mRNA levels $(P>0.05$, Figure 3A). Levels of PD-1, CD28, CTLA-4, and CD25 mRNA in the high-ALB group were not significantly different from those in the low-ALB group (Figure 3B).

The fold change of PD-1 mRNA level was 5.2 in patients with low AGR compared with those with high AGR $(P<0.05$, Figure 3C). In addition, decreased AGR was correlated with high CD25 mRNA levels, with a fold change of $3.3(P<0.05$, Figure $3 \mathrm{C})$. Patients with high TP showed no difference in the expression of PD-1, CD28, CTLA-4, or CD25 mRNA compared with the low-TP group (Figure 3D). We found no significant correlation between other nutritional parameters, including $\mathrm{PA}, \mathrm{Hb}, \mathrm{BMI}$, and PNI, and immune molecule levels (Figure 4). 
A

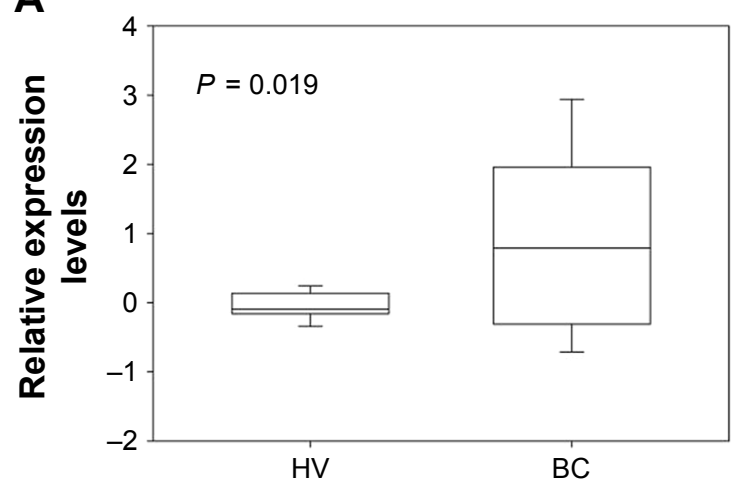

C

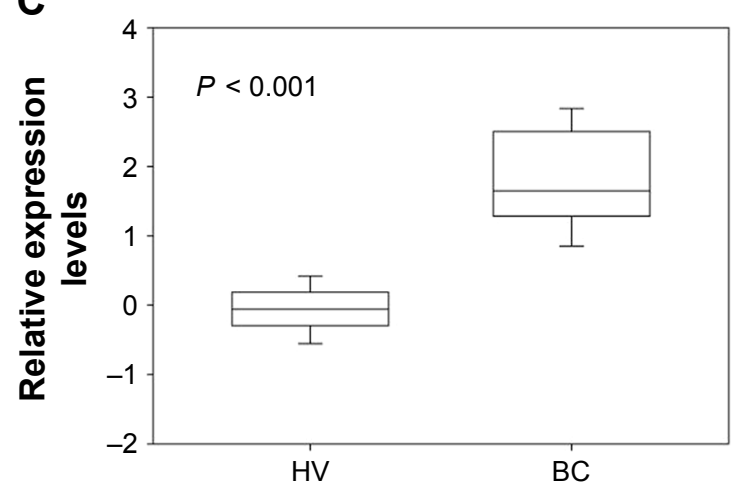

B

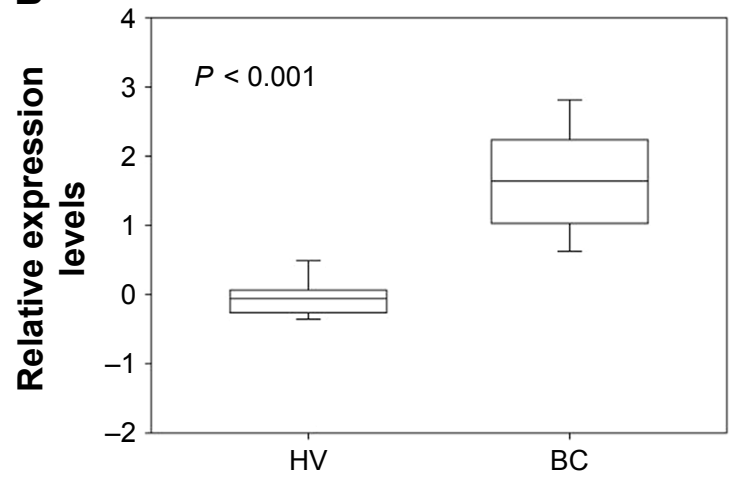

D

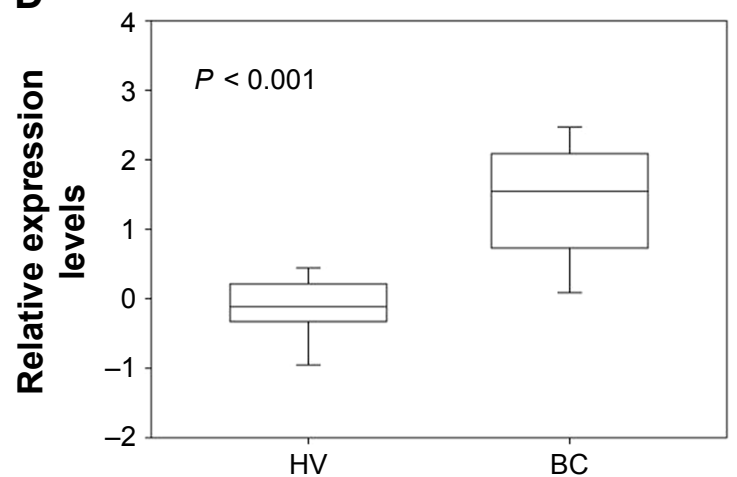

Figure 2 Relative expression levels of (A) PD-I, (B) CD28, (C) CTLA-4, and (D) CD25 in the peripheral blood of BC patients and HVs. Abbreviations: PD-I, programmed cell death protein I; CD28, cluster of differentiation 28; CTLA-4, cytotoxic T-lymphocyte antigen-4; CD25, cluster of differentiation 25; $\mathrm{BC}$, breast cancer; HVs, healthy volunteers.

\section{Discussion}

We demonstrated a 5.2-fold change in PD-1 and a 3.3-fold change in CD25 mRNA levels in patients with low AGR compared with those with high AGR. PD-1 mRNA levels were increased 3.5-fold in patients with high GLB compared with those with low GLB. Stage IV breast cancer patients had poor nutritional status, with lower ALB, AGR, TP, PA, Hb, and PNI values than Stage I-III patients. In addition, breast cancer patients showed higher expression of PD-1, CD28, CTLA-4, and CD25 mRNA than healthy volunteers.

Researchers believe that nutritional status affects innate and adaptive arms of our immune system. The nexus between nutrient metabolism and the immune system occurs at many levels, ranging from endocrine signaling to direct sensing of nutrients by immune cells. ${ }^{25}$ In addition, quantitative and qualitative aspects of nutrition have a profound effect on leukocytes and thereby affect pro-inflammatory carcinogenic effects or anticancer immune responses. Targeted interventions with defined macro- and micronutrients can stimulate anticancer immunosurveillance. ${ }^{26}$ Nutrients also affect immune cell development and function. For example, protein deficiency causes atrophy of primary and secondary lymphoid organs and affects several immune functions, such as lymphocyte proliferation (reduced numbers of both $\mathrm{CD} 4^{+}$ and $\mathrm{CD}^{+} \mathrm{T}$ cells), antibody responses, and IL- 2 and IFN- $\gamma$ production..$^{27}$ Propionate, a nutrient, promotes the development of inflammatory monocytes that, in the lung tissue, differentiate into dendritic cells with an impaired ability to promote the shift of naïve T cells into Th2 cells. ${ }^{28}$

PD-1, a co-inhibitory molecule, is expressed on some immune cells, including $\mathrm{CD}^{+}$and $\mathrm{CD}^{+} \mathrm{T}$ cells, B cells, NK cells, and NK T cells. ${ }^{29}$ After $\mathrm{T}$ cells are activated by tumor antigen, PD-1 is highly expressed and makes T cells exhausted, inhibiting their antitumor immunity. ${ }^{30}$ Regarding the association between PD-1 and the survival of breast cancer patients, some studies found a negative prognostic role of PD-1+ tumor-infiltrating lymphocytes in breast cancer, while others suggested it had a favorable effect on patients' survival in Her-2-enriched breast cancer and breast cancer brain metastases. ${ }^{31-34}$ Here, we found that PD-1 mRNA expression was increased in the peripheral blood of breast cancer patients when compared with healthy volunteers, which is consistent with previous studies. ${ }^{34-37}$ More importantly, there was a 5.2-fold change in PD-1 mRNA levels in patients with low AGR compared with those with high AGR, and a 3.5-fold change in patients with high GLB compared 


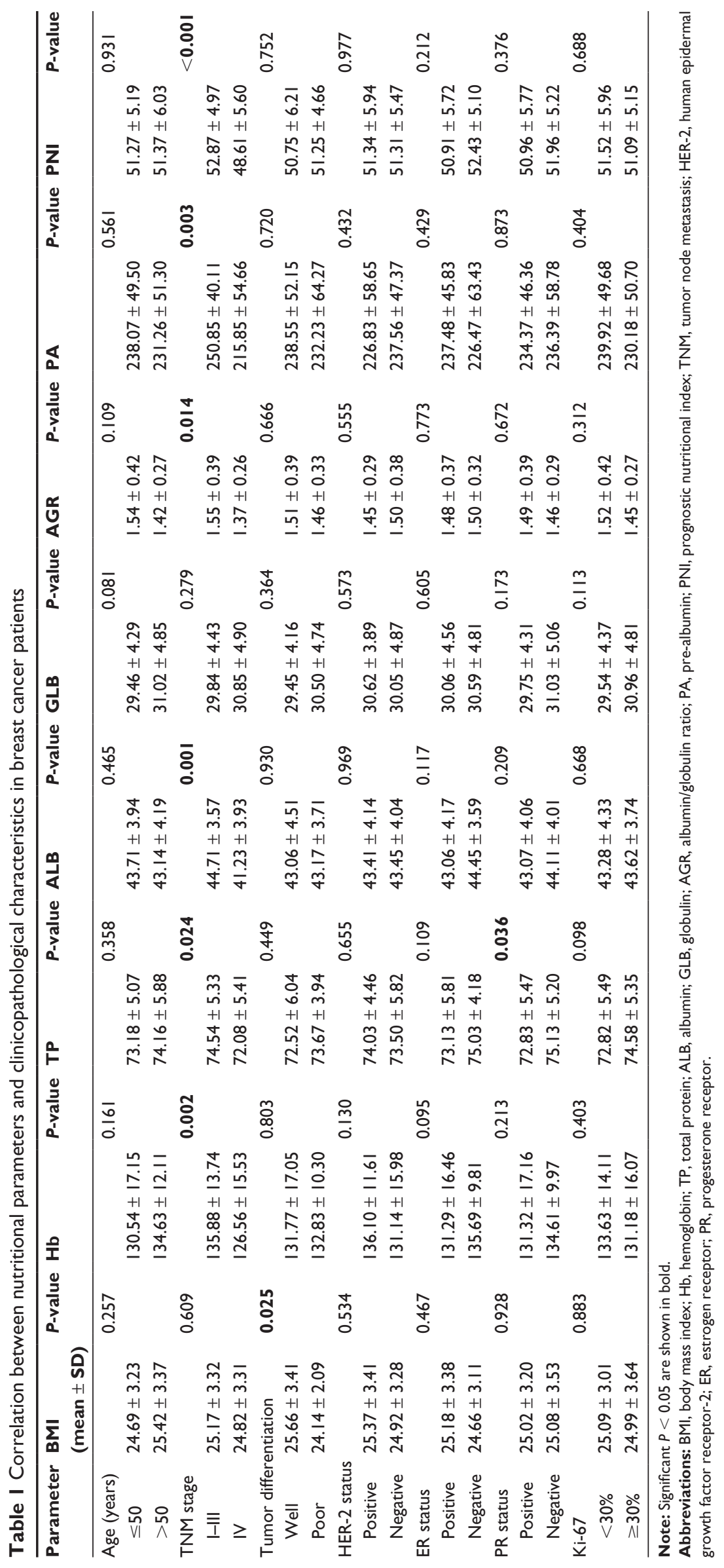



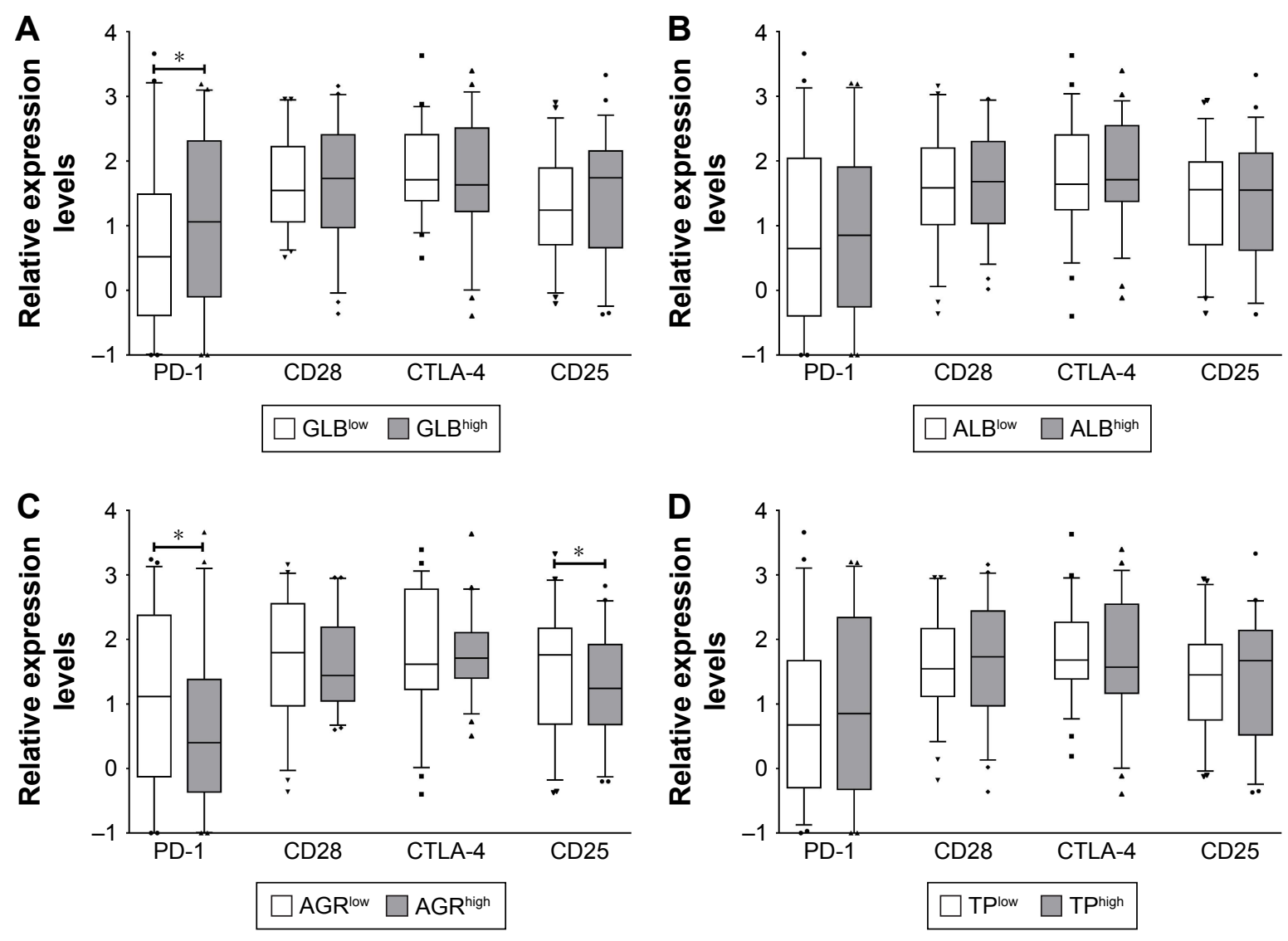

Figure 3 Correlation between relative expression levels of PD-I/CD28/CTIA-4/CD25 and levels of (A) GLB, (B) ALB, (C) AGR, and (D) TP.

Note: $* P<0.05$. Symbols (squares, circles, triangles, and diamond) represent the expression levels of PD-I, CD28, CTLA-4, and CD25, respectively.

Abbreviations: PD-I, programmed cell death protein I; CD28, cluster of differentiation 28; CTLA-4, cytotoxic T-lymphocyte antigen-4; CD25, cluster of differentiation 25; GLB, globulin; ALB, albumin; AGR, albumin/globulin ratio; TP, total protein.

with those with low GLB, consistent with the previous finding that GLB inhibits cell-mediated cytotoxicity and influences PD-1 expression. ${ }^{38}$ However, further studies are needed to investigate the intrinsic mechanisms of the effect of GLB on PD-1/PD-L1 signaling.

CD25 (also known as interleukin-2 receptor alpha) is one of the interleukin-2 receptors, which combines with interleukin-2 to increase Foxp3 expression in $\mathrm{CD}^{+}$ T cells. ${ }^{39,40}$ Previous studies demonstrated a negative effect of soluble CD25 on the survival of patients with acute lymphoblastic leukemia, diffuse large B-cell lymphoma, follicular B-cell non-Hodgkin lymphoma, and T-cell lymphoma. ${ }^{40-43}$ Increased CD25 mRNA expression was found in the peripheral blood of breast cancer patients, consistent with previous findings in B-lineage acute lymphoblastic leukemia and T-cell lymphoma. ${ }^{41,43}$ Interestingly, we found a 3.3-fold change in CD25 mRNA levels in patients with low AGR compared with those with high AGR. The potential mechanisms are as follows. ALB may promote MHC II expression and T-cell activation, but inhibit CD25-dependent Foxp3+ T-cell activation. ${ }^{16}$ However, GLB may activate CD25 expression and consequently increase $\mathrm{CD}^{+}$Foxp $3+\mathrm{T}$ cells, which inhibit cell-mediated cytotoxicity. ${ }^{18}$

CTLA-4 is a co-inhibitory molecule expressed on T cells, $B$ cells, and dendritic cells. CTLA-4 has a homostructure with co-stimulatory molecule CD28, which competes with CD28 for combining with $\mathrm{B} 7$ to inhibit the immune response. ${ }^{30,44}$ CTLA-4 also has an important role in the immunosuppressive function of regulatory $\mathrm{T}$ cells. ${ }^{45}$ Previous studies showed that the presence of CTLA-4+ tumor-infiltrating lymphocytes was negatively correlated with the survival of patients with breast cancer, non-small-cell lung cancer, and esophageal carcinoma. ${ }^{46-49}$ Here, we found that CTLA-4 and CD28 were highly expressed in the peripheral blood of breast cancer patients, indicating that a co-inhibitory signal may be activated. However, there was no correlation between CTLA-4 and nutritional parameters, which may mean there is no intrinsic mechanism between nutritional parameters and CD28/B7 signaling.

To the best of our knowledge, this is the first study to investigate the association between nutritional status and expression of immune checkpoint molecules in breast cancer patients. 

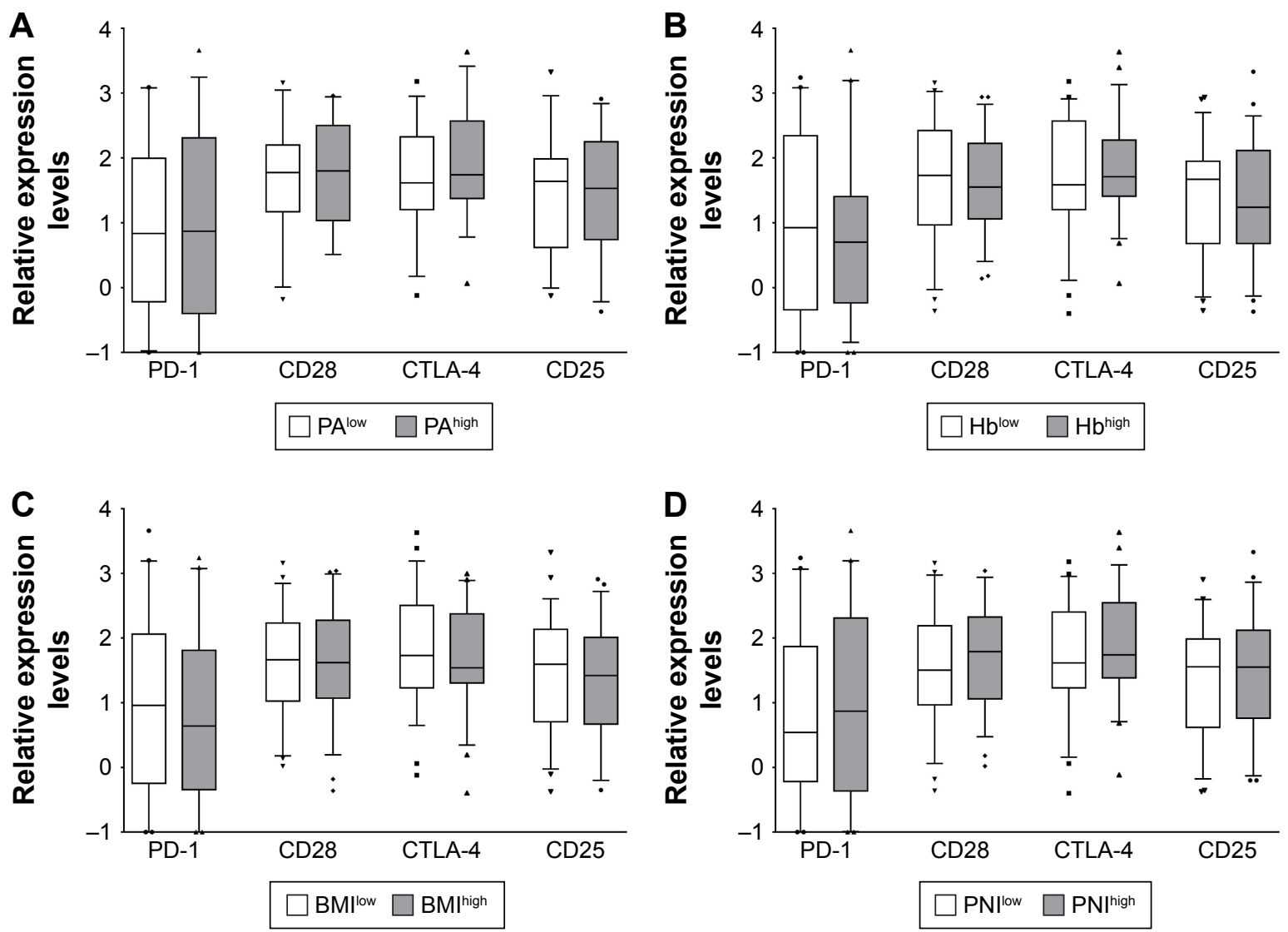

Figure 4 Association between relative expression levels of PD-I/CD28/CTLA-4/CD25 and levels of PA/Hb/BMI/PNI. Association between PD-I/CD28/CTLA-4/CD25 and (A) PA, (B) Hb, (C) BMI, and (D) PNI.

Note: $* P<0.05$. Symbols (squares, circles, triangles, and diamond) represent the expression levels of PD-I, CD28, CTLA-4, and CD25, respectively. Abbreviations: PD-I, programmed cell death protein I; CD28, cluster of differentiation 28; CTLA-4, cytotoxic T-lymphocyte antigen-4; CD25, cluster of differentiation 25; PA, pre-albumin; Hb, hemoglobin; BMI, body mass index; PNI, prognostic nutritional index.

However, the study had several limitations. First, although we found a correlation between AGR and PD-1/CD25 mRNA levels, there was no experiment to explore the underlying mechanisms. Second, parameters of nutritional status and immune molecules may be influenced by antitumor treatments. Third, we did not detect immune markers on a protein basis.

\section{Conclusion}

The present study showed that AGR is negatively correlated with PD-1 and CD25 mRNA levels, while GLB is positively associated with PD-1 mRNA levels, suggesting that nutritional status has an impact on immunity in breast cancer patients. This may support the use of a combination of nutritional treatment and checkpoint inhibitors to treat breast cancer patients.

\section{Disclosure}

The authors report no conflicts of interest in this work.

\section{References}

1. Siegel RL, Miller KD, Jemal A. Cancer statistics, 2017. CA Cancer J Clin. 2017;67(1):7-30.
2. Wen J, Ye F, Li S, et al. The practicability of a novel prognostic index (PI) model and comparison with Nottingham Prognostic Index (NPI) in Stage I-III breast cancer patients undergoing surgical treatment. PLoS One. 2015;10(11):e0143537.

3. Li Q, Meng X, Liang L, et al. High preoperative serum globulin in rectal cancer treated with neoadjunctive chemoradiation therapy is a risk factor for poor outcome. Am J Cancer Res. 2015;5(9):2856-2864.

4. Jiang H, Li H, Li A, et al. Preoperative combined hemoglobin, albumin, lymphocyte and platelet levels predict survival in patients with locally advanced colorectal cancer. Oncotarget. 2016;7(44):72076-72083.

5. Chen Z, Shao Y, Yao H, et al. Preoperative albumin to globulin ratio predicts survival in clear cell renal cell carcinoma patients. Oncotarget. 2017;8(29):48291-48302.

6. Liu X, Meng QH, Ye Y, et al. Prognostic significance of pretreatment serum levels of albumin, $\mathrm{LDH}$ and total bilirubin in patients with nonmetastatic breast cancer. Carcinogenesis. 2015;36(2):243-248.

7. Azab BN, Bhatt VR, Vonfrolio S, et al. Value of the pretreatment albumin to globulin ratio in predicting long-term mortality in breast cancer patients. Am J Surg. 2013;206(5):764-770.

8. Al Murri AM, Wilson C, Lannigan A, et al. Evaluation of the relationship between the systemic inflammatory response and cancer-specific survival in patients with primary operable breast cancer. Br J Cancer. 2007;96(6):891-895.

9. Chen WZ, Yu ST, Xie R, et al. Preoperative albumin/globulin ratio has predictive value for patients with laryngeal squamous cell carcinoma. Oncotarget. 2017;8(29):48240-48247.

10. Park S, Park S, Lee SH, et al. Pretreatment albumin-to-globulin ratio as a predictive marker for tyrosine kinase inhibitor in non-small cell lung cancer. Cancer Biomark. 2016;16(3):425-433. 
11. Bhaskaran K, Douglas I, Forbes H, et al. Body-mass index and risk of 22 specific cancers: a population-based cohort study of 5.24 million UK adults. Lancet. 2014;384(9945):755-765.

12. Cespedes Feliciano EM, Kwan ML, Kushi LH, et al. Body mass index, PAM50 subtype, recurrence, and survival among patients with nonmetastatic breast cancer. Cancer. 2017;123(13):2535-2542.

13. Zhu Z, Li L, Ye Z, et al. Prognostic value of routine laboratory variables in prediction of breast cancer recurrence. Sci Rep. 2017;7(1):8135.

14. Mohri T, Mohri Y, Shigemori T, et al. Impact of prognostic nutritional index on long-term outcomes in patients with breast cancer. World $J$ Surg Oncol. 2016;14(1):170.

15. Yang Z, Zhang B, Hou L, et al. Pre-operative prognostic nutritional index predicts the outcomes for triple-negative breast cancer. Tumour Biol. 2014;35(12):12165-12171.

16. Aubin E, Roberge C, Lemieux R, et al. Immunomodulatory effects of therapeutic preparations of human albumin. Vox Sang. 2011;101(2): 131-137.

17. China L, Maini A, Skene SS, et al. Albumin counteracts immunesuppressive effects of lipid mediators in patients with advanced liver disease. Clin Gastroenterol Hepatol. Epub 2017 Aug 30.

18. Ades EW, Hinson A, Chapuis-Cellier C, et al. Modulation of the immune response by plasma protease inhibitors: I. Alpha 2-macroglobulin and alpha 1-antitrypsin inhibit natural killing and antibodydependent cell-mediated cytotoxicity. Scand J Immunol. 1982;15(1): 109-113.

19. Huh JY, Park YJ, Ham M, et al. Crosstalk between adipocytes and immune cells in adipose tissue inflammation and metabolic dysregulation in obesity. Mol Cells. 2014;37(5):365-371.

20. Picon-Ruiz M, Morata-Tarifa C, Valle-Goffin JJ, et al. Obesity and adverse breast cancer risk and outcome: mechanistic insights and strategies for intervention. CA Cancer J Clin. 2017;67(5):378-397.

21. Ilavska S, Horvathova M, Szabova M, et al. Association between the human immune response and body mass index. Hum Immunol. 2012; 73(5):480-485.

22. Alam I, Larbi A, Pawelec G. Nutritional status influences peripheral immune cell phenotypes in healthy men in rural Pakistan. Immun Ageing. 2012;9(1):16.

23. Edge SB, Compton CC. The American Joint Committee on Cancer: the 7 th edition of the AJCC cancer staging manual and the future of TNM. Ann Surg Oncol. 2010;17(6):1471-1474.

24. Wang W, Shen G, Wu S, et al. PD-1 mRNA expression in peripheral blood cells and its modulation characteristics in cancer patients. Oncotarget. 2017;8(31):50782-50791.

25. Kau AL, Ahern PP, Griffin NW, et al. Human nutrition, the gut microbiome and the immune system. Nature. 2011;474(7351): 327-336.

26. Zitvogel L, Pietrocola F, Kroemer G. Nutrition, inflammation and cancer. Nat Immunol. 2017;18(8):843-850.

27. Calder PC. Feeding the immune system. Proc Nutr Soc. 2013;72(3): 299-309.

28. Trompette A, Gollwitzer ES, Yadava K, et al. Gut microbiota metabolism of dietary fiber influences allergic airway disease and hematopoiesis. Nat Med. 2014;20(2):159.

29. Sharpe AH, Pauken KE. The diverse functions of the PD1 inhibitory pathway. Nat Rev Immunol. Epub 2017 Nov 13.

30. Schildberg FA, Klein SR, Freeman GJ, et al. Coinhibitory pathways in the B7-CD28 ligand-receptor family. Immunity. 2016;44(5): 955-972.

31. Solinas C, Garaud S, De Silva P, et al. Immune checkpoint molecules on tumor-infiltrating lymphocytes and their association with tertiary lymphoid structures in human breast cancer. Front Immunol. 2017; $8: 1412$.
32. Muenst S, Soysal SD, Gao F, et al. The presence of programmed death 1 (PD-1)-positive tumor-infiltrating lymphocytes is associated with poor prognosis in human breast cancer. Breast Cancer Res Treat. 2013;139(3):667-676.

33. Duchnowska R, Peksa R, Radecka B, et al. Immune response in breast cancer brain metastases and their microenvironment: the role of the PD-1/PD-L axis. Breast Cancer Res. 2016;18(1):43.

34. Sun S, Fei X, Mao Y, et al. PD-1(+) immune cell infiltration inversely correlates with survival of operable breast cancer patients. Cancer Immunol Immunother. 2014;63(4):395-406.

35. Kollmann D, Schweiger T, Schwarz S, et al. PD1-positive tumorinfiltrating lymphocytes are associated with poor clinical outcome after pulmonary metastasectomy for colorectal cancer. Oncoimmunology. 2017;6(9):e1331194.

36. Sorensen SF, Demuth C, Weber B, et al. Increase in soluble PD-1 is associated with prolonged survival in patients with advanced EGFRmutated non-small cell lung cancer treated with erlotinib. Lung Cancer. 2016;100:77-84.

37. MacFarlane AWT, Jillab M, Plimack ER, et al. PD-1 expression on peripheral blood cells increases with stage in renal cell carcinoma patients and is rapidly reduced after surgical tumor resection. Cancer Immunol Res. 2014;2(4):320-331.

38. Haller MJ, Gitelman SE, Gottlieb PA, et al. Antithymocyte globulin plus G-CSF combination therapy leads to sustained immunomodulatory and metabolic effects in a subset of responders with established type 1 diabetes. Diabetes. 2016;65(12):3765-3775.

39. Wang X, Rickert M, Garcia KC. Structure of the quaternary complex of interleukin-2 with its alpha, beta, and gammac receptors. Science. 2005;310(5751):1159-1163.

40. Yang ZZ, Grote DM, Ziesmer SC, et al. Soluble IL-2R $\alpha$ facilitates IL-2 -mediated immune responses and predicts reduced survival in follicular B-cell non-Hodgkin lymphoma. Blood. 2011;118(10):2809-2820.

41. Nakase K, Kita K, Miwa H, et al. Clinical and prognostic significance of cytokine receptor expression in adult acute lymphoblastic leukemia: interleukin-2 receptor alpha-chain predicts a poor prognosis. Leukemia. 2007;21(2):326-332.

42. Hashimoto Y, Yokohama A, Saitoh A, et al. Prognostic importance of the soluble form of IL-2 receptoralpha (sIL-2Ralpha) and its relationship with surface expression of IL-2Ralpha (CD25) of lymphoma cells in diffuse large B-cell lymphoma treated with CHOP-like regimen with or without rituximab: a retrospective analysis of 338 cases. J Clin Exp Hematop. 2013;53(3):197-205.

43. Gupta M, Stenson M, O’Byrne M, et al. Comprehensive serum cytokine analysis identifies IL-1RA and soluble IL-2Ralpha as predictors of eventfree survival in T-cell lymphoma. Ann Oncol. 2016;27(1):165-172.

44. Chen L, Flies DB. Molecular mechanisms of T cell co-stimulation and co-inhibition. Nat Rev Immunol. 2013;13(4):227-242.

45. Barbi J, Pardoll D, Pan F. Treg functional stability and its responsiveness to the microenvironment. Immunol Rev. 2014;259(1):115-139.

46. Deng L, Gyorffy B, Na F, et al. Association of PDCD1 and CTLA-4 gene expression with clinicopathological factors and survival in nonsmall-cell lung cancer: results from a large and pooled microarray database. J Thorac Oncol. 2015;10(7):1020-1026.

47. Zhang XF, Pan K, Weng DS, et al. Cytotoxic T lymphocyte antigen-4 expression in esophageal carcinoma: implications for prognosis. Oncotarget. 2016;7(18):26670-26679.

48. Yu H, Yang J, Jiao S, et al. Cytotoxic T lymphocyte antigen 4 expression in human breast cancer: implications for prognosis. Cancer Immunol Immunother. 2015;64(7):853-860.

49. Lu L, Bai Y, Wang Z. Elevated T cell activation score is associated with improved survival of breast cancer. Breast Cancer Res Treat. 2017; 164(3):689-696. 
OncoTargets and Therapy

\section{Publish your work in this journal}

OncoTargets and Therapy is an international, peer-reviewed, open access journal focusing on the pathological basis of all cancers, potential targets for therapy and treatment protocols employed to improve the management of cancer patients. The journal also focuses on the impact of management programs and new therapeutic agents and protocols on

patient perspectives such as quality of life, adherence and satisfaction. The manuscript management system is completely online and includes a very quick and fair peer-review system, which is all easy to use. Visit http://www.dovepress.com/testimonials.php to read real quotes from published authors.

Submit your manuscript here: http://www.dovepress.com/oncotargets-and-therapy-journal 